\title{
DESIGUALDADES HISTÓRICAS: EL GÉNERO COMO FACTOR DE DISCRIMINACIÓN SALARIAL
}

\author{
Maria Jesús Espuny Tomás \\ Profesora Titular de Historia del Derecho y de las Instituciones \\ Universidad Autónoma de Barcelona
}

\begin{abstract}
Este artículo analizará las respuestas al Cuestionario de las Comisiones Provinciales y Locales de Reformas Sociales sobre el trabajo de las mujeres. Nos permitirán visualizar la brecha salarial en los sectores que fueron objeto de su análisis en 1884. Una amplia información oral y escrita que facilita la visión de algunos aspectos bastante semejantes a los actuales. Una desigualdad histórica que se ha ido reproduciendo por la falta de transparencia entre las retribuciones que cobran hombres y mujeres por el mismo trabajo.
\end{abstract}

This article will review the answers to the questionnaire from the Provincial and Local Commissions for Social Reforms on women's work. These answers will allow us to consider the wage gap in the sectors that were the object of their analysis in 1884. An extensive oral and written information that facilitates the vision of some aspects quite similar to the current ones. This historical inequality has been reproduced by the lack of transparency between the salaries paid to men and women for the same work.

Title: Historical inequalities: the gender as a salary discrimination cause.

Palabras clave: género, salario, discriminación

Key words: gender, salary, discrimination.

IUSLabor 2/2018, ISSN 1699-2938, p. 360-385

DOI: 10.31009/IUSLabor.2018.i02.17 


\section{Sumario}

1. Presentación.

2. La cuestión Social y el trabajo femenino: los orígenes de la desigualdad.

3. Salarios y trabajo de las mujeres en las respuestas al cuestionario de las Comisiones Provinciales y Locales de Reformas Sociales.

3.1. ¿Dónde trabajaban las mujeres?

3.2. Desigualdad salarial.

4. Conclusiones.

5. Bibliografía. 


\section{Presentación}

"Al trabajar la mujer en unión con el hombre nunca es la directora, ni siquiera se la tiene por igual a éste, sino que figura como auxiliar. Así, su trabajo, aunque sea el mismo, siempre se aprecia menos". .

"La cuantía del salario no influye para nada en la imperfección de la obra, como lo prueba la tendencia de la gran industria a ir cada vez más substituyendo con el de la mujer y del niño el trabajo del hombre, procurando en primer término la baja del salario sin preocuparse de los resultados de la producción, que día a día van siendo más independientes del esfuerzo intelectual del obrero"2.

La brecha salarial entre hombres y mujeres ha sido objeto de debates intensos durante los últimos meses. La dimisión de la corresponsal jefa de la BBC en China, Carrie Grace, al descubrir que sus compañeros cobraban el $50 \%$ más, puso de manifiesto la diferencia salarial y actuó en consecuencia. Las protestas no se hicieron esperar incluso a nivel internacional: el 8 de mayo de 2018 se convirtió en una gran manifestación que superó todas las previsiones. Sin embargo, se trata de una desigualdad histórica que se ha ido reproduciendo por la falta de transparencia entre las retribuciones que cobran hombres y mujeres por el mismo trabajo. Junto a este aspecto hemos de estimar la consideración normativa de la mujer y de los niños como "medias fuerzas", la importancia que en la vida profesional femenina adquiere el cuidado a terceros (hijos y/o ascendientes), la jornada laboral que no siempre puede llegar a ser completa, y las consecuencias finales en la jubilación, también con una pensión más reducida. Una estructura patriarcal que se mantiene aún vigente. Las respuestas al Cuestionario de las Comisiones Provinciales y Locales de Reformas Sociales nos permitirán visualizar la brecha salarial en los sectores que fueron objeto de su análisis en 1884 y valorar con la perspectiva histórica algunos aspectos bastante semejantes a los actuales.

\footnotetext{
${ }^{1}$ Reformas Sociales, Información escrita practicada en virtud de la Real Orden de 5 de diciembre de 1883, Madrid, Manuel Minuesa de los Ríos, Tomo II, 1890, p. 158. Edición facsímil, Centro de Publicaciones. Ministerio de Trabajo y Seguridad Social, 1985.

${ }^{2}$ Reformas Sociales, cit., Tomo II, 1890, pp. 116-117. Salario, Grupo IX del cuestionario, informe de D. Enrique Borrel.
} 


\title{
2. La cuestión social y el trabajo femenino: los orígenes de la desigualdad.
}

\begin{abstract}
"La mujer trabajadora fue un producto de la revolución industrial, no tanto porque la mecanización creara trabajos para ella alli donde antes no había habido nada, como porque en el transcurso de la misma se convirtió en una figura problemática y visible ${ }^{\text {,3 }}$.

C'est que la femme devenue ouvrière n'est plus une femme".
\end{abstract}

Los problemas que se producen en el mundo del trabajo en la fase inicial del liberalismo y de la industrialización provocan el acceso indiscriminado de las mujeres y de los niños a la mayoría de los oficios. Uno de los elementos que integran la cuestión social es precisamente la preocupación por el trabajo de las llamadas "medias fuerzas" que conlleva una aproximación humanitaria a este colectivo.

En un paso que va más allá de la caridad privada e incluso de la beneficencia pública, el Estado asume una función protectora para garantizar la salud material y moral de las clases trabajadoras. El acento humanitario preside las tareas legislativas en esta materia e inspira el lenguaje de la caridad de las primeras normas. Junto a las invocaciones a la caridad y a la piedad surgirán auténticos instrumentos jurídicos para regular los aspectos fundamentales de las relaciones laborales: las leyes de accidentes de trabajo, de mujeres y niños, de descanso dominical o el Reglamento de la inspección de trabajo, son un ejemplo $^{5}$. La legislación intentará suavizar asperezas, evitar luchas entre el capital y el trabajo en la vida de la gran industria que encuentra a faltar los lazos que habían presidido las relaciones entre maestros y artesanos en etapas anteriores ${ }^{6}$.

El salario de la mujer era el complemento al exiguo jornal del padre o del marido ${ }^{7}$. La

\footnotetext{
${ }^{3}$ SCOTT, J. W., "La mujer trabajadora en el siglo XIX" en DUBY, G. Y PERROT, M., Historia de las mujeres en Occidente, Tomo IV, Madrid, Taurus minor, 2000, pp. 427-461.

${ }^{4}$ SimON, J., L'ouvrière, Paris, Hachette, 1864, p. V.

5 Montoya Melgar, A., Ideología y lenguaje en las leyes laborales de España (1873-1978), Madrid, Civitas, 1992, pp. 28 y ss. "lenguaje de la caridad y lenguaje del miedo"; Etapa de "caridad legal” según RuIz De GriJAlBA, A., El contrato de trabajo ante la razón y el derecho, Madrid, Francisco Beltrán, 1902, 2a. Edición, 1922; ARIAS DE VELASCO, J., "El derecho y la caridad" en Revista General de Legislación y Jurisprudencia 83 (1893) pp. 40-57.

6 DATO E IRADIER, E., "Significado y representación de las leyes protectoras del trabajo" a la Revista General de Legislación y Jurisprudencia, 114 (1909), pp. 5-28; PÉREZ GONZÁLEZ, V., “Apuntes sobre la cuestión social" en Revista General de Legislación y Jurisprudencia 100 (1902), pp. 566-582 y 101 (1902), pp. 5-25.

${ }^{7}$ Reformas Sociales, cit., Tomo I, p. 107, respuesta del Sr. Villegas en la sesión del 14 de diciembre de
} 
inferioridad física producida por la débil fisiología femenina, y por las limitaciones que se le atribuían, fuesen culturales, jurídicas o incluso intelectuales justificaban el carácter secundario de su retribución que era siempre inferior a la del varón. La mujer se convierte así en una competidora del hombre en el mercado laboral por su salario ${ }^{8}$. El trabajo a domicilio funciona como una excusa para cobrar aún menos?

La mujer comparte sus obligaciones laborales con el trabajo doméstico; los autores critican la dejación de sus funciones como esposa y como madre y el peligro que tiene para su moralidad el trato frecuente con individuos de distinto sexo ${ }^{10}$.

\section{Salarios y trabajo de las mujeres en las respuestas al cuestionario de las Comisiones Provinciales y Locales de Reformas Sociales.}

La creación por el Real Decreto el 5 de diciembre de 1883 de la "Comisión para el estudio de las cuestiones que interesan a la mejora o bienestar de las clases obreras tanto agrícolas como industriales y que afectan a las relaciones entre el capital y el trabajo", supone el inicio de una etapa en la aparecen las primeras y más decisivas muestras de intervencionismo estatal en las cuestiones sociales ${ }^{11}$. Uno de los objetivos será: "Trabajo de los niños y mujeres en las fábricas, en las minas y en los campos; máximum de las horas de trabajo según la edad; relación entre las horas de trabajo y la asistencia a la escuela; casos en que estas medidas deberán dar lugar a sanción penal"12.

1884: "La mujer busca trabajo fuera del hogar por aumentar el haber de su familia, porque, como he dicho ya, es insuficiente el jornal del obrero".

${ }^{8}$ BALCELLS, A., Trabajo industrial y organización obrera en la Cataluña contemporánea 1900-1936, Barcelona, Laia, 1974, p. 12; Reformas Sociales, cit. Tomo IV, p. 44: un obrero de Alicante, Federico Helliur, se lamenta que: "en algunos trabajos, propios de hombres, se vayan introduciendo mujeres, como está sucediendo, por ejemplo, en los telares mecánicos y en la nueva industria de sombreros".

${ }^{9}$ Reformas Sociales, cit., Tomo I, p. 183, Sr. Pérez Agua en la sesión del 6 de enero de 1885: "porque el burgués dice a una oficiala: me vas a hacer esto en tu casa. Pero ¿con que intención es? Para que se lo haga más barato, porque el echa sus cuentas y dice: en su casa hace treinta veces más".

${ }^{10}$ Reformas Sociales, cit., Tomo I, p. 108, Sr. Villegas: "cuando se plantea el conflicto entre el hambre y la decencia, ésta triunfa a veces,; pero cuando se acomete de cierta manera a la honradez, y hay en una casa un hombre libertino que pone a la mujer en la alternativa de ceder o morirse de hambre, si ésta le acosa, cederá al fin, y desde entonces aquella criatura se ha perdido para siempre"; Reformas Sociales, Tomo III, pp. 111-115: "La Unión manufacturera del arte de la seda, comunicó que las mujeres oyen en las fábricas de Valencia conversaciones de hombres, y que en las de las afueras, si bien trabajan solas, sufren en cambio, las exigencias y torpes deseos de los capataces, sin que de ello se ocupen los patronos". ${ }^{11}$ Montero García, F., "La polémica sobre el intervencionismo y la legislación obrera en España: 18901900 (parte I): el debate académico" en Revista de Trabajo 59-60, 3er y $4^{\circ}$ trimestres 1980, pp. 119-165, CASTILLO, S., "Estudio introductorio" a la edición facsímil de Reformas Sociales, cit., Tomo I, especialmente, pp. LXIX-CXLI

${ }^{12}$ Gaceta de Madrid del 10 de diciembre de 1883, artículo 2, 3er. 
Se organizan Comisiones Provinciales y Locales de Reformas Sociales de acuerdo con una Real Orden de 28 de mayo de 1884 con la finalidad de abrir una amplia información oral y escrita sobre el estado y las necesidades de las clases trabajadoras de acuerdo con las facultades reconocidas en el artículo $5^{\circ}$ del Decreto fundacional. Esta información se había de conseguir por las respuestas a un largo cuestionario de 223 preguntas divididas en 32 apartados ${ }^{13}$.

Se establecen Comisiones Provinciales en todas las capitales, excepto en Madrid donde funciona la Comisión Central, y Comisiones Locales en aquellos lugares que respondían a zonas conflictivas industriales, agrícolas o mineras. La composición de las Comisiones estaba equilibrada en sus inicios, pero se inclinó poco a poco a favorecer a las representaciones profesionales liberales, especialmente del ámbito jurídico en detrimento del sector obrero. Cada Comisión enviaba su memoria y los informes escritos que se habían recibido.

El cuestionario sobre el trabajo de las mujeres corresponde al apartado XIV y comprende las preguntas de la 93 a la 104:

"93. Trabajo de la mujer en la casa y fuera de ella; condiciones en que se verifica en este último caso y sus consecuencias.

94. ¿Busca la mujer trabajo fuera del hogar por absoluta necesidad, o por el deseo de aumentar el haber de la familia?

95. ¿Trabajan las mujeres en las mismas industrias que los varones? ¿Trabajan las mismas horas que éstos?

96. ¿Se dedican, dentro del hogar, a trabajos que se relacionan con los talleres?

97. Influjo de la vida del taller o de la fábrica en la moralidad de la mujer soltera y de la casada, y en el modo de llenar la última su cometido en la familia.

98. Cuando se emplean mujeres en las mismas industrias que los varones haciendo un trabajo análogo o idéntico, ¿qué relación hay entre el salario que perciben

\footnotetext{
${ }^{13}$ CAStillo, S., "El reformismo en la Restauración, Del Congreso Sociológico de Valencia a la Comisión de Reformas Sociales" en Estudios de Historia Social 30 (1984), pp. 21-78; Álvarez Junco, J., "La Comisión de Reformas Sociales: Intentos y realizaciones" en De la beneficencia al bienestar social, Seminario de Historia de Acción Social, Madrid, Consejo General de Colegios Oficiales de Diplomados en Trabajo Social y Asistentes Sociales-Siglo XXI, 1986, pp. 147-153; CALLE VelaSCO, M. D., de la, La Comisión de Reformas Sociales, 1883-1903. Política social y conflicto de intereses en la España de la Restauración, Madrid, Ministerio de Trabajo y Seguridad Social, 1989; PAlacio MorenA, J. I., La institucionalización de la reforma social en España (1883-1924). La Comisión y el Instituto de Reformas Sociales, Madrid, Ministerio de Trabajo y Seguridad Social, 1988; BERNALDO DE QUIRÓs, C., "El Instituto de Reformas Sociales" en Revista de Trabajo 25 (1969), pp. 153-158 y a la Revista General de Legislación y Jurisprudencia 122 (1913), pp. 209-216; Studia Historica, vol. II, nº 4 (1984) dedicado a la Comisión de Reformas Sociales; Elorza, A., Iglesias, M. C., "La fundación de la Comisión de Reformas Sociales" en Revista de Trabajo 25 (1969), pp.75-105.
} 
respectivamente?

99. ¿Se emplean las mujeres en las industrias insalubres o peligrosas? ¿En qué proporción toman parte en las faenas del campo?

100. Industria mercantil: Servicio de las mujeres en el comercio; ramos en que alternan con los varones; ventajas o inconvenientes de que haya en un establecimiento dependientes de ambos sexos.

101. Industria tipográfica: ¿Prestan algún trabajo en las imprentas las mujeres?

102. Transportes marítimos: ¿Se ocupan las mujeres en las faenas de carga y descarga de los muelles? ¿Qué jornal ganan y en qué proporción está con el salario que se paga a los varones? ${ }^{14}$.

103. Industria minera: ¿Trabajan las mujeres en las minas? ¿Qué jornal ganan y en qué proporción está con el salario que se paga a los varones?

104. Servicios públicos: ¿Están encomendados algunos de éstos, ya sean nacionales, provinciales o municipales a las mujeres?".

Los resultados del cuestionario se reunieron en cinco tomos, publicados entre 1889 y 1893, cuya distribución es la siguiente: en el Tomo I (1889), se recoge la información oral ante la Comisión Central de Madrid, en el Tomo II (1890), la información escrita practicada por la Comisión de Reformas Sociales de Madrid, en el Tomo III (1891), la información oral y escrita practicada por la Comisión de Reformas Sociales de la provincia de Valencia, en el Tomo IV (1892), la información oral y escrita practicada por la Comisión de Reformas Sociales de las provincias de Alicante, Ávila, Badajoz, Burgos y Cáceres, finalmente en el Tomo V (1893), la información oral y escrita practicada por la Comisión de Reformas Sociales en las provincias de La Coruña, Jaén, Navarra, Oviedo, Palencia y Vizcaya. Toda esta documentación favorecerá la tramitación y presentación de un proyecto de Ley de trabajo de las mujeres y de los niños que se anuncia en la exposición de motivos del Real Decreto de 1890 que reorganiza la Comisión de Reformas Sociales ${ }^{15}$.

\footnotetext{
${ }^{14}$ Reformas Sociales, cit., Tomo II, p. 463, en la respuesta del Arte de imprimir hay un reto a la pregunta de la Comisión: “(...) habréis visto muelles, y en ellos, medio desnudas y cubiertas de polvo y de sudor, infelices mujeres trabajando. Preguntad, pues, si lo ignoráis, que salario ganan, qué trato las dan, y otras particularidades necesarias; pero no preguntéis, sabiéndolo, si las mujeres se ocupan en las faenas de los muelles".

${ }^{15}$ GARCIA NineT, J. I. "Elementos para el estudio de la evolución histórica del derecho español del trabajo: regulación de la jornada de trabajo desde 1855 a 1931", $1^{\text {a }}$ parte, Revista de Trabajo 51 (1975), pp. 66-70, proposición de Ley de Manuel Dávila sobre el trabajo de niños, menores y de las mujeres empleadas en la industria, según el autor, el antecedente más directo de la Ley de 13 de marzo de 1900 pp. 76-87 exposición pormenorizada de la vida parlamentaria en los diferentes proyectos de Ley de mujeres y niños; CALLE Velasco, La Comisión..., cit. pp. 277-295 referencias a la proyección legislativa de los trabajos de la Comisión.
} 
Se recogieron las respuestas más variadas desde algunas organizaciones anarquistas y socialistas hasta centros oficiales y privados, como la Facultad de Derecho de la Universidad Central de Madrid, la Institución Libre de Enseñanza y diferentes Ateneos. La desigualdad de las respuestas obreras explica las diferencias en la actuación de unas Comisiones y de las otras. No pueden valorarse de la misma forma los informes de algunas sociedades obreras que habían sido estudiados y discutidos previamente, como en el caso de Valencia y Madrid, a las respuestas emitidas delante de las fuerzas sociales de su población, Ávila y Alcoy, o las que provienen de los distintos oficios, como en los casos de Palencia, Onteniente o Plasencia ${ }^{16}$.

Es indiscutible que el desarrollo de la gran industria empeoró la condición de las clases trabajadoras, "llevando al taller a seres destinados únicamente a las labores del hogar; ha llevado al taller a la mujer, logrando así que los brazos no sobrantes para la producción ganen un salario inferior al que deben percibir, porque todos sabemos que los esfuerzos que la mujer realiza dentro del taller son muchas veces iguales, si no superiores, a los del hombre, y en cambio es siempre menos retribuida"17. La maquinaria y la entrada en los talleres de las mujeres y los niños, es por lo que se produce la "baja en el salario"18. Es indiscutible que la participación laboral femenina perjudica a los demás trabajadores ${ }^{19}$.

Una de las consecuencias más significativas recogidas con referencia al trabajo de la mujer y en varios de los apartados del cuestionario y que ya se ha comentado, es la competencia entre el trabajo y el salario del marido y el de la esposa, pues el sueldo de ésta no llegará a cubrir los gastos que conlleva su ausencia del hogar familiar. Ello se une a la alteración del buen funcionamiento del hogar, a la perversión de la moralidad de la mujer y a su debilidad fisiológica. Un informante reconoce la gran demanda de mujeres para ciertos trabajos que son solicitadas porque "se les paga mal", aunque "muchas veces se las ve suplantando a los hombres en las faenas más penosas" 20. Un

16 IGLESIAS, M. C. Y ElORZA, A., Burgueses y proletarios. Clase obrera y reforma social en la Restauración, Barcelona, Editorial Laia, 1973 y en Revista de Trabajo 25 (1969); PALACIO, La institucionalización..., pp. 27-41.

${ }^{17}$ Reformas Sociales, cit., Tomo I, p. 59-60, intervención del Sr. Gómez en la sesión del 2 de noviembre de 1884, el informante, refiere que al ir a pedir trabajo unos obreros en Manresa se les dijo: "a vosotros no se os quiere; preferimos a las mujeres porque nos sirven por un salario más barato". Reconoce que la mujer también trabaja en ebanistería.

${ }^{18}$ Reformas Sociales, cit., Tomo I, pp. 79-80, Sr. Diego Abascal en la sesión del día 7 de diciembre de 1884.

${ }^{19}$ Reformas Sociales, cit., Tomo I, p. 215-216, intervención de Pablo Iglesias en la sesión del 11 de enero de 1885 afirma que en su programa se plantea la reducción de horas de trabajo para que pueda incluirse también a la mujer.

${ }^{20}$ Reformas Sociales, cit., Tomo II, pp. 376-385, D. Ramiro P. Liquiñano, pide que el trabajo de la mujer sea metódico y que esté en relación con su naturaleza física y propone su reglamentación, pp. 376-385. 
episodio recogido en la información oral de Valencia en relación con la huelga de la fábrica de sedería de Llombart: el fabricante se negó a la demanda de los huelguistas y montó una nueva industria fuera de la capital, donde sólo trabajaban mujeres ${ }^{21}$.

Este artículo analizará, aunque no de forma exclusiva, las respuestas a las preguntas que hacen referencia al salario de las mujeres. También se examinarán otras informaciones paralelas relacionadas con el tema, aunque no se hallen contempladas en las preguntas incluidas en el apartado de referencia. Otros aspectos derivados del estudio pormenorizado de las preguntas del cuestionario en relación con el trabajo femenino han sido objeto de anteriores investigaciones ${ }^{22}$.

\section{1. ¿Dónde trabajaban las mujeres?}

"La mujer se destina con preferencia a la manufactura y el hombre a la máquina o al trabajo corporal propiamente dicho. Es mayor la participación de los hombres en las manufacturas que la de las mujeres en las fábricas, por más que se observe en los centros industriales manifiesta propensión a sustituir el trabajo de los hombres por el de las mujeres y los niños". Esta afirmación es una de las respuestas al grupo XIV del Cuestionario y corresponde a Don Alejandro San Martín ${ }^{23}$. Distingue entre el trabajo económico, el que desarrolla la mujer en el hogar y el productivo que comprende las tareas agrícolas y artesanas en la zona castellano-manchega. Analiza las condiciones de trabajo de la mujer fuera de la casa que varían notablemente según sean casadas o solteras, a domicilio, en el taller, en la fábrica, en la calle, en los lavaderos, en el campo de su propia población o en poblaciones diferentes, en hospitales, asilos, conventos o

\footnotetext{
${ }^{21}$ Reformas Sociales, cit., Tomo III, p. 166, Sesión de 19 de octubre de 1884, informante, Sr. Vives Mora, representante del Ateneo Casino Obrero de Valencia.

${ }^{22}$ ESPUNY TOMÁs, M. J., "La primera legislación social protectora de la mujer: una perspectiva comparada" en RAmOS VÁZQUEZ, I. (coordinadora), Derecho y Trabajo en el siglo XIX, Madrid, Dykinson, 2017, pp. 81-147 ESPUNY TOMÁs, M. J., "El servicio doméstico: la historia jurídica de una exclusión continuada" en ESPUNY TOMÁs, M. J./GARCIA GONZÁLEZ, G. (coordinadores), Relaciones laborales y empleados de hogar: reflexiones jurídicas, Madrid, Dykinson, 2014, pp. 27-60; ESPUNY TOMÁs, M. J., "Políticas legislativas y regulación especial del trabajo a domicilio", VII Encuentro de investigadores sobre el franquismo, Universidad de Santiago de Compostela, 2010, pp. 17-26; ESPUNY TOMÁs, M. J., "Legislació histórica i Gènere" en BODELón, E./GIMÉNEZ, P., Desenvolupant els drets de les dones: àmbits d'intervenció de les polítiques de gènere, Barcelona, Diputación de Barcelona, 2008, pp. 15-31; EsPuNY TOMÁs, M. J., "El projecte de Llei d' intervenció obrera en la gestió de les industries" en Ysás Solanes, M., Segona República i Món Jurídic, Mataró, Editorial Càlamo, 2007, pp. 65-87; EsPUNY TOMÁs, M. J., "Fisiologia i moral en la legislació social" en Àgor@ 2000, Jornades per la igualtat d'oportunitats i responsabilitats a la vida laboral i familiar, Barcelona, Generalitat de Catalunya, Institut Català de la Dona, 2001, pp. 137-141.

${ }^{23}$ Reformas Sociales, cit., Tomo II, pp. 149-169 corresponden al amplio informe de D. Alejandro San Martín
} 
colegios. Señala las características de las regiones, de las comarcas o de las poblaciones donde son más frecuentes ${ }^{24}$.

El apéndice al dictamen del Sr. San Martín, a cargo de Don Anselmo Fuentes, sobre el "trabajo de las mujeres" se refiere a las operarias de las Fábricas Nacionales de Tabacos, una industria "donde el hombre no puede hacer competencia a la mujer", "operarias que por derecho propio elaboran con exclusión del otro sexo, los cigarros" pero en donde sufren un registro diario al salir del establecimiento ${ }^{25}$. Condiciones laborales también difíciles para las trabajadoras en el sector de los tejidos en La Coruña donde se hacen "grandes descuentos por un pequeño descuido de tiempo a la hora de entrada, o bien se las despide o deja de abonar lo hecho a destajo por una ligera imperfección en el producto" 26 .

El informe al Grupo XXXI del cuestionario sobre las Industrias explotadas por el Estado fue elaborado por el Director General de Rentas Estancadas. En él se hace un detenido análisis al jornal que perciben las operarias de las fábricas de tabacos, que cuando tienen una "habilidad excepcional" sobre todo las de talleres de labores especiales pueden doblar el sueldo de los varones; a pesar de ello se insiste en que " $\mathrm{el}$ jornal de la operaria, aun cuando reducido en muchos casos puede considerarse, como auxilio a la familia"27.

Una referencia al trabajo de las costureras y de las modistas la encontramos en el Grupo XIII del cuestionario dedicado a informar sobre las horas de trabajo: "trabajan con exceso, a veces doce horas, les pagan por cada camisa tres reales y a lo más cuatro, y ponen el hilo",28.

El informe de D. Ramiro Pérez Liquiñano justifica la alta incorporación de las mujeres al trabajo en las fábricas: "las máquinas ahorrando fuerza muscular, la gran demanda de mujeres para ciertos trabajos, solicitadas porque se las paga mal, la ignorancia y el atraso en que se las tiene, la manera de ser de los Estados modernos, que llaman para otros fines al sexo masculino, los ejércitos, las profesiones, la empleomanía y el

\footnotetext{
${ }^{24}$ ESPUNY TOMÁs, M. J., "Políticas de empleo y trabajo a domicilio ¿Una cuestión de género (19181926)?" en I Congreso Iberoamericano de relaciones laborales y recursos humanos (Sevilla, 28-29 de enero de 2016). Análisis detallado del informe de D. Alejandro San Martín.

${ }^{25}$ Un "Apéndice al Dictamen del Sr. San Martín”; Id., pp. 170-172 a cargo de D. Anselmo Fuentes, en relación a las operarias de las Fábricas Nacionales de Tabaco.

${ }^{26}$ Reformas Sociales, Tomo V, cit. p. 43. Informe oral de La Coruña, sesión del 4 de noviembre de 1884, con ello "no se tiende a perjudicar a las operarias, sino a enseñarlas y estimularlas para que se perfeccionen en el trabajo".

${ }^{27}$ Reformas Sociales, Tomo II, cit. pp. 36-38.

${ }^{28}$ Reformas Sociales, Tomo II, cit. p. 140-141, Informe de D. José Rodríguez Mourelo.
} 
comercio alejan un considerable número de hombres de la industria, produciendo todas estas causas la concurrencia de mujeres a las fábricas"29.

"El sexo es también un motivo de desigualdad: porque si bien se comete una grave injusticia rebajando a la mujer, no puede desconocerse que los dos sexos tienen diferentes aptitudes. La mujer es superior al varón por su sensibilidad delicada y por su aptitud para sufrir ciertos infortunios, pero el hombre la aventaja en dotes intelectuales" afirma en su informe sobre el apartado VI (retribución del trabajo: salario) D. Julio Campos del Riego ${ }^{30}$.

Los diferentes tipos de trabajo, según las industrias de las provincias consultadas se pone de manifiesto en la provincia de Valencia. En la industria lanera las mujeres desempeñan sus tareas en trabajos "que le son adecuados" como tirar la lanzadera, hacer canillas, franjas, limpiar la urdimbre y ya empiezan a trabajar en los tejidos en que a la lana se une el algodón, y en los que se hacen con telares metálicos. En Alcoy, las mujeres de la industria pañera tienen faenas especiales, separadas de los varones y trabajan nueve horas ${ }^{31}$. El bloque de la seda comprende cuatro ramos: hilados, torcidos, tintes y tejidos. En los hilados "sólo emplean mujeres que, si por la naturaleza del trabajo, no se encuentran fuera de las condiciones propias de su sexo, por el número de horas que dura su jornada han de faltar a los deberes y conveniencias de la familia, o a abandonar el trabajo cuando toman estado". En los torcidos "se emplean principalmente mujeres, que son retribuidas a jornal". "En los tejidos se emplean mujeres retribuidas a jornal, más que a destajo, pero siempre con una remuneración inferior a la de los hombres, lo cual es causa de abaratamiento de la mano de obra en este arte". En las serrerías mecánicas, la carpintería y la ebanistería, las mujeres se ocupan del pulimento y otros trabajos "que no exceden de las fuerzas de su sexo". Por el contrario, en la fabricación de las cerillas y fósforos se emplean gran número de mujeres que perciben un jornal en una ocupación "contraria a las condiciones de su sexo". La mujer valenciana trabaja en la fabricación de azulejos, ocupaciones que "no son impropias de su sexo, pero produciendo una crisis penosa para los obreros de este oficio", también en la fabricación de ladrillo y teja.

La fabricación de alpargatas emplea a bastantes mujeres con un trabajo que es "soportable para su sexo" y que puede desempeñar en su casa con un salario con que hacer la competencia a lo que ganan en otras industrias. El pulimento de los abanicos, normalmente una industria que permite desarrollarla en talleres casi domésticos emplea a mujeres como teladoras, en el taller del fabricante o constituyendo cada maestra un

\footnotetext{
${ }^{29}$ Reformas Sociales, Tomo II, cit., pp. 376-385.

${ }^{30}$ Reformas Sociales, Tomo II, cit., pp. 403, recogido en el Acta de la sesión de 27 de febrero de 1885.

${ }^{31}$ Reformas Sociales, Tomo IV cit., p. 103, Informe de la Corporación de fabricantes de paños de Alcoy.
} 
pequeño taller en su casa con sus oficiales. Organización semejante la que llevan a cabo las preparadoras de zapatos que normalmente se llevan a casa el trabajo o lo desarrollan en pequeños talleres, bajo la dirección de una maestra, en los que preparan, cosen forros, gomas y tirantes, siendo retribuidas a tanto la pieza. La industria del encaje es doméstica y propia para la mujer ${ }^{32}$.

El trabajo en el domicilio familiar es haciendo gorras, zapatos, alpargatas o sastrería. La máquina de coser juega en todos estos casos un papel fundamental. Las mujeres valencianas trabajan en fábricas (seda, azulejos...) ocupando los puestos de trabajo de los hombres que han de trabajar como camareros en fondas y cafés. En algunas industrias locales las mujeres trabajan por conveniencia, para aumentar el bienestar familiar o para preparar su futuro matrimonio. En toda la información oral y escrita está presente la influencia fatal que el trabajo tiene para la mujer; se detallan diferentes organizaciones donde los padres trabajan con las hijas, los hermanos con las hermanas, como medida para evitar perjuicios a la moralidad ${ }^{33}$.

Las mujeres en Plasencia trabajan en su casa en el propio hogar doméstico y el cuidado de su familia, "si desempeñan alguno no relacionado con estas obligaciones, se reducen a las labores de su sexo" que confeccionan para la venta, y más frecuentemente para atender a encargos que reciben ${ }^{34}$. En Pamplona, dentro del hogar muchas mujeres y niños se dedican a la confección de cajitas de fósforos, que presentan por tareas todas las mañanas en las fábricas ${ }^{35}$.

En Tudela manifiestan que han desaparecido por completo las industrias domésticas: "hace algunos años, se veían a las mujeres reunidas en las casas en las noches de invierno, junto al hogar, con su útil llamado rueca, que era una caña, teniendo en el extremo superior una forma de roca o castillejo, adonde rodeaban el copo de lino, cáñamo o lana que habían de trabajar, y asiendo con la mano estas materias, salía como un cabello largo, que se extendía en forma de hilo e iba rodeándose en el otro instrumento llamado huso. Estas hilaturas de lino, cáñamo o lana las empleaban después los obreros de talleres de mano en sus respectivos tejidos "36.

\footnotetext{
${ }^{32}$ Reformas Sociales, cit., Tomo III, pp. 12-19, "Precedentes" de la Comisión Provincial de Valencia.

${ }^{33}$ Reformas Sociales, cit., Tomo III, pp. 111-115: "La Unión manufacturera del arte de la seda, comunicó que las mujeres oyen en las fábricas de Valencia conversaciones de hombres, y que en las de las afueras, si bien trabajan solas, sufren en cambio, las exigencias y torpes deseos de los capataces, sin que de ello se ocupen los patronos".

${ }^{34}$ Reformas Sociales, cit., Tomo IV, pp. 536-537. Memoria de la Comisión de Plasencia.

${ }^{35}$ Reformas Sociales, cit., Tomo V, pp. 300. Informe de los Sres. Hijos de Martín María Guelbenzu, Cascante, fabricantes de fósforos.

${ }^{36}$ Reformas Sociales, cit., Tomo V, p. 246. Informe de la Real Sociedad de Amigos del País de Tudela.
} 
Las mujeres de Oviedo trabajan en las "llamadas labores del sexo", unas veces cosiendo para establecimientos o talleres y otras por encargo de particulares; acostumbran a llevar a casa tareas relacionadas con zapaterías, sastrerías y modistas. En muchas fábricas trabajan en las mismas industrias que los hombres, aunque no realizan las mismas operaciones, en las fábricas de vidrios y de loza se dedican al decorado; sus actividades se reducen a labores mecánicas de última categoría como empaquetado, lavado, clasificación y escogido de materiales y otras análogas, siempre de escasa retribución de 0'82 a 1 pesetas; trabajan las mismas horas que los obreros, pero no trabajan por la noche ${ }^{37}$.

En las fábricas de mosaico, de azulejos y de loza ordinaria las mujeres trabajan diez horas, las mismas horas que el varón, en trabajos distintos. En las fábricas de seda hay dos clases, unas situadas fuera de la ciudad donde solo trabajan las mujeres doce horas a jornal. En las situadas en la ciudad trabajan varones y mujeres todos a destajo, "pudiendo dejar la fábrica cuando quieren", lo cual no deja de favorecer las conveniencias domésticas. Las fábricas de las afueras están exclusivamente levantadas para que trabajen en ellas toda clase de tejidos sólo las mujeres. Los hombres en las indicadas fábricas no ocupan ningún telar y sólo se ocupan en hacer cumplir el régimen de la fábrica, que en algunas de ellas es duro, y estar al cuidado de componer los desperfectos que puedan ocurrir en los telares. Las mujeres trabajan a jornal trece horas, o sea doce de continuo trabajo, un cuarto de hora para el almuerzo por la mañana y tres cuartos de hora para la comida del mediodía. Trabajan las mismas horas que los hombres y se esfuerzan mucho más en el trabajo que aquéllos, porque se hallan vigiladas y para que no puedan distraerse ni un solo momento ${ }^{38} \mathrm{En}$ las grandes fábricas de las afueras, las mujeres no pueden salir de la fábrica hasta finalizar la jornada laboral $^{39}$.

En general la jornada laboral es la misma en zapatería, sastrería y alpargatería; sin embargo, a pesar del calificativo entre trabajos "apropiados o no apropiados" para la mujer, la preocupación por su moralidad está siempre presente ${ }^{40}$.

El trabajo en las imprentas sólo lo desempeñan las mujeres cuando el marido es el propietario de una pequeña industria que no le permite tener operarios por su escaso

\footnotetext{
${ }^{37}$ Reformas Sociales, cit., Tomo V, p. 455-457. Información oral de la Comisión Provincial de Oviedo.

${ }^{38}$ Reformas Sociales, cit., Tomo III, Apéndice n ${ }^{\circ}$ 51, pp. 551-554, informe de la Sociedad de Socorros del Arte de la Seda.

${ }^{39}$ Reformas Sociales, cit., Tomo III, pp. 247-248, sesión del23 de noviembre de 1884 bajo la presidencia de D. Eduardo Pérez Pujol, informante, la Unión manufacturera del arte de la seda.

${ }^{40}$ Reformas Sociales, cit., Tomo I, p. 107, continuando con la respuesta del Sr. Villegas: "parece que están vestidas de almazarrón por el polvillo colorado del mineral de hierro procedente de la estación de Guarnizo".
} 
rendimiento; en este caso es ayudado por sus esposas e hijas "ya dando tinta en las prensas, ya plegando, dorando y aun echando letra a las cajas"41.

Las mujeres trabajan en la industria papelera escogiendo las clases de trapos que constituye la primera materia y que se destina a la confección del papel ${ }^{42}$. Respecto al trabajo de las mujeres en las industrias de tejidos de lana, se informa en Onteniente que sus condiciones son buenas, la misma respuesta la encontramos para las industrias de tejidos de seda y algodón, añadiendo que trabajan las mismas horas que los varones ${ }^{43}$. También esta afirmación respecto a las condiciones laborales se repite en los almacenes de naranjas, confección de cajas, sastrerías, etc. ${ }^{44}$. En Burgos trabajan fuera de su domicilio unas 440 operarias, generalmente solteras, en las fábricas de papel ${ }^{45}$.

En la industria alpargatera trabajan mujeres "tanto en casa de los fabricantes como en las suyas propias, y que el objeto que las mueve a ocuparse de esta clase de trabajos obedece a las necesidades que tienen en sus respectivas familia ${ }^{, 46}$. En Plasencia, fuera de su domicilio las mujeres trabajan en industrias como las sombrererías, talleres de modistas y costura en casas particulares ${ }^{47}$. Las jóvenes solteras de Ferrol se dedican a la costura fuera de su casa y trabajan las mismas horas que los hombres.

Las actividades de las mujeres en la provincia de Oviedo se desarrollan en el campo, en las minas, en las obras públicas o particulares (al cestón), en las fábricas de tabacos y de cerillas, en la venta y conducción del pescado fresco, en la reventa de muchos artículos de primera necesidad, en la preparación de conservas alimenticias, en la elaboración de queso y manteca, en las sastrerías y confección de objetos de moda y en la fabricación de hilados, tejidos y cierto género de bordados (blondas y puntillas) ${ }^{48}$.

Las mujeres se ocupan a las faenas agrícolas en la provincia de Valencia, básicamente las más ligeras como la recolección de aceituna, de uva o de otros frutos ${ }^{49}$. Trabajan las mismas horas que los varones y su salario es menor que el de ellos. Practican las

\footnotetext{
${ }^{41}$ Reformas Sociales, cit., Tomo V, p. 298. Informe del Sr. Sixto Díaz de Espada de Pamplona.

${ }^{42}$ Reformas Sociales, Tomo III, cit., pp. 265-266, informaciones orales de los pueblos de las provincias de Valencia, informantes de la industria papelera de Onteniente, bajo la presidencia de D. Francisco Montes Mora, Alcalde de la ciudad; Tomo IV, cit. p. 44, Informe de la Comisión provincial de Alicante, en relación con el trabajo de la mujer en la industria del papel y de borras.

${ }^{43}$ Reformas Sociales, Tomo III, cit., pp. 268, 270,

${ }^{44}$ Reformas Sociales, Tomo III, cit., p. 287, informaciones orales de los pueblos de las provincias de Valencia, sesión de 28 de octubre de 1884 en Alcira.

${ }^{45}$ Reformas Sociales, Tomo IV, cit., p. 376. Memoria de la Comisión Provincial de Burgos.

${ }^{46}$ Reformas Sociales, Tomo III, cit., p. 272.

${ }^{47}$ Reformas Sociales, Tomo IV, cit., p. 536-537. Memoria de la Comisión de Plasencia.

${ }^{48}$ Reformas Sociales, Tomo IV, cit., p. 376. Memoria de la Comisión provincial de Oviedo.

${ }^{49}$ Reformas Sociales, Tomo III, cit., p. 280.
} 
operaciones agrícolas que se permiten como escarda, vendimia, siega y cogida de aceitunas ${ }^{50}$. El número de faenas del campo en que la mujer toma parte es limitado y poco importante se reduce a empapelar naranjas y a la recolección citada, dadas sus especiales condiciones físicas.

La mujer del trabajador agrícola asalariado en la provincia de Ávila desarrolla una amplia actividad para completar el salario del marido: "se dedica al lavado de ropas para dos o tres casas; vende la leche de los ganados; cuida los animales domésticos para utilizar sus productos, que también vende; coge hierbas del campo para mantenerlos, fabrica escobas de pajas o plantas silvestres; atiende en las faenas agrícolas, mediante un jornal a las operaciones de escarda y trilla; utiliza el espigueo durante la recolección; amasa el pan que consume la familia y el tiempo que le sobra lo dedica a recoser la ropa de su marido e hijos y a dar a éstos la más trivial y rudimentaria educación" $"$.

En Burgos, un $50 \%$ de las mujeres trabajan en las tareas agrícolas y "con la rudeza de los hombres". En la capital, "cuatrocientas cuarenta mujeres se dedican a trabajos de taller" ${ }^{\prime 52}$. En Cáceres la mujer se dedica básicamente a los trabajos domésticos y a las faenas agrícolas donde toma parte "en una proporción media a la del hombre" ${ }^{53}$.Las mujeres que se dedican al trabajo rural en Plasencia lo hacen en las mismas condiciones que los hombres y expuestas a iguales influencias climatológicas, siendo su jornada de la misma duración o más, porque no disfruta de los ratos de descanso de aquellos. La ocupación de la mujer en la agricultura no exige trabajo muscular o rudo esfuerzo, pues se les reservan las operaciones más suaves entre las que ofrece el cultivo del campo o la recolección de frutos ${ }^{54}$. En Navarra la mujer ayuda "alguna vez a su marido principalmente en la montaña, donde el suelo es menos productivo y el clima más templado, en las faenas del campo cuando es pequeño propietario o arrendatario de tierras; también en la época de la recolección, en que las operaciones han de hacerse con rapidez y se prestan al auxilio de la mujer ${ }^{, 55}$.

En Ferrol la mujer toma gran parte en el laboreo de las tierras que algunas de ellas realizan casi por completo, a fin de que los hombres se desplacen a la ciudad para ganar

\footnotetext{
${ }^{50}$ Reformas Sociales, Tomo III, cit., pp. 372-373, informe escrito de la Comisión local de Sueca; Tomo IV, cit. p. 96, informe del Gremio de labradores de Alcoy.

${ }^{51}$ Reformas Sociales, Tomo IV, cit., p. 131. Memoria de la Comisión provincial de Ávila.

${ }^{52}$ Reformas Sociales, Tomo IV, cit., p. 422. Información escrita de Burgos, Informe del Círculo de Obreros.

${ }^{53}$ Reformas Sociales, Tomo IV, cit., p. 472-473. Informe de la Comisión Provincial de Cáceres.

${ }^{54}$ Reformas Sociales, Tomo IV, cit., p. 536-537. Informe de la Comisión Provincial de Plasencia.

${ }^{55}$ Reformas Sociales, Tomo V, cit. p. 203. Memoria de la Comisión de Navarra.
} 
un jornal $^{56}$.

La mujer alcoyana trabaja en su propia casa en la industria de cerillas y como ayudante del tejedor ${ }^{57}$. Dentro del hogar en Ávila hacen pequeños trabajos para fuera como camisería, sastrería, zapatería, etc. ${ }^{58}$.Subsiste en Burgos el trabajo doméstico de los tejidos de punto, guantería y zapatillería con un estipendio "insignificante" a pesar de la competencia de los penados en estos trabajos. La mayoría de las mujeres operarias trabajan en sus casas principalmente con las zapatillas ordinarias de abrigo, chalecos, trajes femeninos y otros análogos, excepto las que trabajan en algunas industrias, como la de fabricación de papel $^{59}$.

Los trabajos que se llevan a cabo en el hogar en la provincia de Jaén se reducen a sogas y tomizas de esparto, a la confección de trajes de mina, denominados hatillos, calzoncillos para los mineros, gorras, baberos, camisas y esparteñas ${ }^{60}$. En Navarra, las mujeres jóvenes y solteras salen de casa de sus padres a servir; ejercen algunos trabajos como costureras o planchadoras, "más que por necesidad por el afán de vestir con cierto lujo"61.

La mujer en La Coruña "abandona su vivienda" para trabajar en las fábricas de tabacos, en las de fósforos, tejidos, salazón, en algunos talleres y en el servicio de mandaderas y pasan las horas desde muy temprano hasta la noche con muchas privaciones para ganar la corta retribución de 3,4 y 6 reales diarios, y no en todas ocasiones ${ }^{62}$.

En la descripción de los trabajos femeninos en Linares aparece la dedicación de las mujeres casadas a criar o lactar otros niños, siendo costumbre dejar a sus hijos con parientes y hasta con amigos para dedicarse a servir durante el día y dormir en su casa, pues las solteras y viudas sin hijos son las que duermen en las casas donde sirven. También se citan otros trabajos como el lavado de ropa, de la población obrera o de

\footnotetext{
${ }^{56}$ Reformas Sociales, Tomo V, cit. p. 126. Memoria de la Comisión de Ferrol.

${ }^{57}$ Reformas Sociales, Tomo IV, cit., pp.44-45.

${ }^{58}$ Reformas Sociales, Tomo IV, cit., p. 227. Información escrita de Ávila a cargo de D. Isidoro Benito Lapeña.

${ }^{59}$ Reformas Sociales, Tomo IV, cit., p. 373. Memoria de la Comisión Provincial de Burgos: "la funesta competencia, determinada por el trabajo de los penados, ha hecho desaparecer las industrias domésticas de zapatería, alpargatería, hilados y guarnecidos en máquinas de coser, ramos a los que generalmente se hallaban dedicados los niños, los inutilizados y las mujeres"; id. p. 376; id., p. 393: "las industrias domésticas rinden un producto ínfimo especialmente por la competencia del presidio", id., p. 426: "En cuanto los establecimientos penitenciarios, no hay para qué decir su maligno influjo en todos los oficios".

${ }^{60}$ Reformas Sociales, Tomo V, cit., p. 164. Información del Ingeniero Jefe de las minas de Linares.

${ }^{61}$ Reformas Sociales, Tomo V, cit. p. 203. Memoria de la Comisión de Navarra

${ }^{62}$ Reformas Sociales, Tomo V, cit., p. 35. Memoria de la Comisión de La Coruña.
} 
casas acomodadas. Mujeres y muchachos trabajan como aguadores, obteniendo buenos jornales durante el verano (de 75 céntimos a 1 peseta) ${ }^{63}$.

En las costas del Norte y en muchas de Levante, la mujer comparte con el hombre el trabajo de la carga y la descarga en los muelles, siempre como auxiliar. En Santander y en los puertos cercanos al Bidasoa, realizan trabajos muy rudos como las bateleras de Pasages. Si trabajan como jornaleras, se cobran en pescado, que ellas mismas lavan y venden como pueden, aunque nunca llegan a sacar un salario mediano ${ }^{64}$.

En las tareas del mar las mujeres están descritas como "desaliñadas nereidas", manejan diestramente el remo, guiando diminutas embarcaciones para la recolección del marisco y figurando en las lanchas que patronea su padre. En las fábricas se turnan en los oficios, unas "espichan y embarillan" las sardinas, otras las lavan. Las que tienen mayor habilidad acomodan las sardinas en los cascos o en los barriles para exportarla, éstas son las que perciben un mayor salario según la destreza para asentar los pescados. Otra industria relacionada con la pesca era la construcción de redes a mano que según informan ha ido perdiendo su anterior protagonismo. Otro trabajo estrictamente femenino es el de las pescaderas que llevan a la plaza el pescado propio o que han comprado $^{65}$.

Sin embargo, realizará tareas similares en las mismas industrias que los varones, así tenemos constancia de su trabajo en los tejares de Madrid, como peón de albañil en Santander, en operaciones de carga y descarga de las embarcaciones e incluso en la minería ${ }^{66}$. En Ferrol las mujeres de "clases humildes y menos instruidas" se dedican a las faenas más rudas, como el acarreo de agua a las casas y la carga y descarga de cal, carbón, leña, etc. Sirven también como peones en las obras públicas y privadas ${ }^{67}$.

La situación laboral de la mujer en el sector de la minería se limita a la preparación mecánica de los minerales para hacer el primer apartado de mineral rico y zafra. Trabajan también en las lavas, pero los trabajos que ejecutan no se encargan normalmente a los hombres, sino a los muchachos con el mismo horario y el mismo sueldo. El salario de la mujer era siempre la mitad del salario del hombre, aunque sus

\footnotetext{
${ }^{63}$ Reformas Sociales, Tomo V, cit., pp. 176-177. Informe del Ingeniero Jefe de Linares.

${ }^{64}$ Reformas Sociales, Tomo II, cit., pp. 163-164. Informe de D. Alejandro San Martín.

${ }^{65}$ Reformas Sociales, Tomo V, cit. pp. 102-103, Información escrita de La Coruña, industria de la pesca en Galicia. Extenso desarrollo del trabajo femenino en el sector, con descripción pormenorizada de las condiciones laborales de las mujeres.

${ }^{66}$ Reformas Sociales, Tomo I, cit., p. 107, continuando con la respuesta del Sr. Villegas: "parece que están vestidas de almazarrón por el polvillo colorado del mineral de hierro procedente de la estación de Guarnizo".

${ }^{67}$ Reformas Sociales, Tomo V, cit., p. 126. Memoria de la Comisión de Ferrol.
} 
trabajos fueran iguales ${ }^{68}$.

En las minas de Oviedo las mujeres se ocupan en las minas únicamente del lavado o cribado de los carbones, alternando de día y de noche. El número de mujeres ocupadas en la industria minera del Concejo de Mieres es de 40, poco más o menos. Son todas solteras; y como quiere que se "resiente algún tanto su moralidad, pierden bastante ante la opinión por el solo hecho de trabajar en las minas. Enferman con frecuencia y la mayor parte de ellas están anémicas o cloróticas ${ }^{69}$.

\subsection{Desigualdad salarial.}

La diferencia del salario entre la mujer y el hombre se justifica por las razones siguientes: " 1 a . La menor fuerza de la mujer, aunque para ciertas labores como el desmote en las minas, tenga ésta más habilidad; $2^{a}$. La menor fijeza de las mujeres en toda labor; $3^{\mathrm{a}}$. Su costumbre de cantar y hablar, que perjudica notablemente la cantidad de trabajo; $4^{\mathrm{a}}$. la menor resistencia del organismo de la mujer para la fatiga, rigores del clima, etc.; $5^{\text {a }}$. La consideración de que al trabajar la mujer en unión con el hombre nunca es la directora, ni siquiera se la tiene por igual a éste, sino que figura como auxiliar. Así, su trabajo, aún cuando sea el mismo, siempre se le aprecia menos"70.

En igualdad de trabajo, la mujer gana menos jornal que el hombre ${ }^{71}$.La mujer sustituye al hombre en las faenas más penosas con un sueldo inferior: "insignificancia del jornal". Se denuncia la competencia salarial con el hombre: "aparte de la competencia que hace al trabajo y salario del obrero, el producto del salario que gana la obrera no alcanza a satisfacer la demasía del gasto que ocasiona su falta del hogar"72. La ocupación de las mujeres en el sector industrial se fomenta porque perciben un sueldo inferior al del hombre y esta diferencia se pone de manifiesto en la mayoría de las informaciones ${ }^{73}$.

\footnotetext{
${ }^{68}$ Reformas Sociales, Tomo IV, cit., p. 473 respecto al trabajo de la mujer en las minas de Cáceres; Tomo V, cit., Informe del Ingeniero Jefe de las Minas de Linares, pp. 176-177; Informe que emite el Ingeniero de Minas D. Mariano Zuaznávar referente al establecimiento minero de Orbó de la Sociedad Esperanza de Reinosa pp. 533-539: "A pesar de contar las minas con un personal de 300 operarios y unas 250 personas más entre mujeres y niños (...)”.

${ }^{69}$ Reformas Sociales, Tomo V, cit., p. 375. Memoria de la Comisión de la Provincia de Oviedo.

${ }^{70}$ Reformas Sociales, Tomo II, cit., pp. 158-159. Informe de D. Alejandro San Martín recogiendo las opiniones del Sr. Mourelo.

${ }^{71}$ Reformas Sociales, Tomo IV, cit., p. 177. Información oral de Ávila, respuesta de D. José Sayanes. En el mismo grupo D. Casiano Cotillo afirma que a la mujer se le dan 4 reales y medio, cuando el peón gana 7 y el oficial, 12 .

${ }^{72}$ Reformas Sociales, Tomo II, cit., pp. 381-382, Informe de D. Ramiro Pérez Liquiaño en la sesión del 7 de febrero de 1885 .

${ }^{73}$ Reformas Sociales, Tomo I, Sesión del 2 de noviembre de 1884, informe del Sr. Gómez, pp. 59-67; Sesión del 7 de diciembre de 1884, Sr. Diego Abascal, pp. 81-82; Sesión del 14 de diciembre de 1884,
} 
Aunque el trabajo de la obrera es menos pesado que el de los hombres, en determinadas ocasiones se las emplea en lugar de éstos por un jornal que está, por término medio, reducido a la tercera parte de los varones ${ }^{74}$. El trabajo de la mujer hace una competencia "perjudicial a los varones, pues haciéndolo más barato, pero menos perfecto, sin embargo, es aprovechado por la codicia o ligereza de algunos maestros. Tal sucede con las que trabajan de sastre y las que se ocupan en la pesca"75.

La Sociedad de socorros del arte de la seda de Valencia manifestó la dificultad de establecer de un modo exacto la relación entre el salario según el tipo de producto elaborado y si el tipo de trabajo: así en los llamados glasés (4 metros, 500 centímetros por día) la mujer a jornal en las fábricas de las afueras y el hombre a destajo en la capital, ellas cobraban 1'50 pesetas y el hombre 3'50 pesetas. En las fábricas de las afueras a la mujer no le vale más que seis reales, pues éste es el "jornal mezquino" que se da a las que trabajan en perfección en los telares ${ }^{76}$.

La Unión manufacturera, manifestó que en dichos trabajos del arte de la seda ganan las mujeres de un 30 a un 60 por 100 menos que los varones, y que se les obliga además aumentar su trabajo, amenazándolas con la pena de rebajarlas a operaciones menos retribuidas, o halagándolas con el estímulo de ascender a a otras operaciones mejor $\operatorname{pagadas}^{77}$.

El jornal del tapicero informa la Comisión provincial de Ávila es de 24 y aún de 30 reales, y el de la tapicera de 9 a 10. La sastra llega a ganar a veces un real diario, y que si trabaja a destajo gana tanto o más que un hombre ${ }^{78}$.

Las mujeres en Palencia trabajan en los talleres de mantas como jornaleras, cardadoras e hilanderas percibiendo un salario mucho más reducido que el de éstos ${ }^{79}$.

informe del Sr. Villegas, pp. 107-108; Sesión del 6 de enero de 1885, informe del Sr. Pérez Agua, pp. 162184: “(...) si (la mujer) va a trabajar es para ayudar a la familia, porque a veces el burgués ha despedido a su padre o a su hermano que ganaban más".

${ }^{74}$ Reformas Sociales, Tomo IV, cit. p. 64, información escrita. Memoria de la Comisión local de Alcoy; Tomo IV, cit., p. 228, información escrita de Ávila: "el salario que aquí percibe la mujer cuando se emplea en idéntico o análogo trabajo que el varón suele exceder poco de la mitad del salario".

${ }^{75}$ Reformas Sociales, Tomo V, cit. p. 43. Información oral de La Coruña, sesión de 4 de noviembre de 1884 .

${ }^{76}$ Reformas Sociales, Tomo III, cit., pp. 114 y pp. 551-553. Apéndice núm. 51, citado.

${ }^{77}$ Reformas Sociales, Tomo III, cit., p. 113: "se sujeta a las pobres mujeres durante las horas de trabajo al más duro y riguroso silencio, y que se las obliga a que cada una lleve tres latas, no más para poder salir a los excusados, medida dura, aun cuando parezca motivada por frecuentes abusos".

${ }^{78}$ Reformas Sociales, Tomo IV, cit. p. 177. Sesión del día 9 de noviembre de 1884, Comisión provincial de Ávila.

${ }^{79}$ Reformas Sociales, Tomo V, cit. p. 511. Informe de los obreros de la fabricación de mantas de Palencia. 
En una fábrica de mosaicos los salarios de las mujeres varían en función de las edades, superando incluso en las etapas más iniciales, donde las jóvenes de doce a quince años cobran de 0,50 a una peseta, mientras que los muchachos ente doce a catorce años llegan a 1, 25 pesetas. En Ayora, las mujeres ganan menos que los hombres. En Sueca de acuerdo con la información de su Ateneo, ganan la mitad que los varones. En relación con las tareas agrícolas ganan la mitad del jornal que los varones aunque se ocupan de trabajos más ligeros ${ }^{80}$.

En la industria papelera de Onteniente, el salario de los hombres oscila entre las 1, 50 pesetas a 2, 75 pesetas, el de las mujeres entre 50 y 75 céntimos $^{81}$.

Las mujeres en Burgos que en el campo se dedicar a excavar, suelen percibir un jornal equivalente a los dos tercios del que ganan aquellos ${ }^{82}$. En Villarcayo, la mujer se ocupa de las labores propias de la casa y además agrícolas como los hombres, trabajando menos horas que ellos y ganando una tercera parte menos de salario ${ }^{83}$. En Cáceres, la mujer se ocupa de las faenas del campo en una proporción media a la del hombre, en los trabajos más suaves y en las mismas horas por la mitad del salario de los hombres ${ }^{84}$.

La relación entre el salario del obrero y de la mujer en La Coruña, está "siempre en contra de ésta" en la relación de 1 a $3^{85}$. En Navarra, "excepto en la fabricación de tejidos en blanco y en la fabricación de fósforos" la mujer no se dedica a los mismos trabajos que los hombres, y en estas industrias "vienen a obtener el mismo jornal que aquellos". Lamenta el informante que la mujer no trabaja en la industria tipográfica, donde sería necesaria pues son trabajos de "agilidad, gusto y ortografía" 86 .

En Pamplona según un informe librado a la Comisión, cuando se emplean en las mismas industrias que los varones, el salario es igual para ambos. Sorprende esta afirmación cuando en la industria de la fabricación de fósforos se afirma que los hombres ganan de 4 a 8 reales y las mujeres de 3 a 4 reales, según la edad y aptitud, estando a jornal y las destajistas reciben de 2'5 a 5 o 6 reales, según los trabajos hechos que presenten ${ }^{87}$.

\footnotetext{
${ }^{80}$ Reformas Sociales, Tomo III, cit., p. 114.

${ }^{81}$ Reformas Sociales, Tomo III, cit., pp. 265-266; Tomo IV, cit., p.115, informe de "La Unión Papelera de Alcoy".

${ }^{82}$ Reformas Sociales, Tomo IV, cit., p. 396.

${ }^{83}$ Reformas Sociales, Tomo IV, cit., p. 455

${ }^{84}$ Reformas Sociales, Tomo IV, cit., p. 472-473. Informe de la Comisión Provincial de Cáceres.

${ }^{85}$ Reformas Sociales, Tomo V, cit., p. 35. Memoria de la Comisión de La Coruña.

${ }^{86}$ Reformas Sociales, Tomo V, cit., p. 203. Memoria de la Comisión de la provincia de Navarra.

${ }^{87}$ Reformas Sociales, Tomo V, cit., p. 300-301, la igualdad salarial que afirma el Sr. D. Pedro Galbete de Pamplona es diferente de la de los fabricantes de fósforos y también de las condiciones del Sr. Director de
} 
Las operarias de la alpargatería de Onteniente ganan un jornal de 20 a 40 céntimos y los hombres de una peseta a 25 céntimos. En la industria papelera el salario de los hombres oscilaba entre 1'50 pesetas a 2'75, el de las mujeres entre 50 y 62 céntimos y el de los niños entre 25 y 75 céntimos $^{88}$. En Liria trabajan diez horas y ganan de 50 céntimos a una peseta en el mismo sector. Como operaria agrícola en la misma población la mujer gana un jornal de 50 céntimos y los niños 75; los hombres por término medio una peseta con 25 céntimos $^{89}$.

El trabajo de la mujer en Plasencia se retribuye con poco más de la mitad que el hombre, aunque se trate de labores similares ${ }^{90}$. En Ferrol, la mujer en todas las industrias a las que se dedica sólo consigue un salario muy inferior al hombre ${ }^{91}$. Aunque el hombre y la mujer no hacen idénticos trabajos en Linares, el tipo de jornal de la mujer en todas las operaciones que ejecuta es de una peseta, o sea la mitad o menos de lo que el obrero gana en los suyos ${ }^{92}$.

En la cuenca minera de Asturias las mujeres ganan 1,05 pesetas, alternan el trabajo de día y de noche, según la intensidad de la demanda de carbón, pero siempre con el mismo salario que es la mitad que el de los hombres y menor que el de los muchachos que ganan entre 1'25 y 1'50 pesetas ${ }^{93}$ En las minas de Mieres ganan de jornal de 1'25 a 1'50 pesetas, la mitad de lo que cobran los adultos ${ }^{94}$. El jornal de las mineras en general es bastante inferior al de los hombres y se diferencia poco del de los muchachos, variando entre dos y ocho reales, siendo el término medio de una peseta ${ }^{95}$.

En el sector marítimo la mujer trabajando diez horas diarias llega a cobrar entre un mínimo de 75 céntimos y un máximo de 1 peseta con cincuenta céntimos, esta cantidad

la Tejería Mecánica de Pamplona que afirma tener a dos extranjeras en trabajos especiales con idéntico salario que lo obreros.

${ }^{88}$ Reformas Sociales, Tomo III, Informaciones escritas de los pueblos de la provincia (Valencia), cit., p. 266. Informaciones orales de los pueblos de las provincias de Valencia, informantes de la industria papelera de Onteniente, bajo la presidencia de D. Francisco Montes Mora, Alcalde de la ciudad.

${ }^{89}$ Reformas Sociales, Tomo III, cit. p. 354-355.

${ }^{90}$ Reformas Sociales, Tomo IV, cit., p. 537. Memoria de la Comisión de Palencia; id. , pp. 554-555. Información oral de Palencia: "el jornal de la mujer es la mitad que el que gana el hombre".

${ }^{91}$ Reformas Sociales, Tomo V, cit., p. 126. Memoria de la Comisión de Ferrol.

${ }^{92}$ Reformas Sociales, Tomo V, cit., p. 177. Informe del Ingeniero Jefe de las Minas de Linares.

${ }^{93}$ Reformas Sociales, Tomo V, cit., p. 457. Información oral de la Provincia de Oviedo.

${ }^{94}$ Reformas Sociales, Tomo V, cit., p. 375. Informe de la Comisión de Oviedo.

${ }^{95}$ Reformas Sociales, Tomo II, cit. p. 165. Informe detallado de D. Alejandro San Martín, recogiendo la estadística minera de 1882, sobre el trabajo de las mujeres en el exterior y en el interior: "Se aprecia mucho el trabajo de las mujeres en este género de industria porque lo hace con esmero y cierta delicadeza que el hombre carece" 
corresponde a la mitad del jornal del hombre ${ }^{96}$. Las mujeres se ocupan de la carga y descarga en los muelles de Vizcaya, ganando por su trabajo un jornal notablemente inferior al hombre ${ }^{97}$ En la pesca llamada del bolichó en la playa del Nazareth se reparte el producto de la pesca, los niños una cuarta parte, las mujeres la mitad y parte entera los hombres ${ }^{98}$.

\section{Conclusiones}

El origen de la discriminación salarial se produce durante la revolución industrial. El sueldo de la madre de familia equilibraba el presupuesto doméstico ante el escaso sueldo del marido. La ocupación de las mujeres se generaliza porque perciben un salario inferior al de los hombres. Hemos podido comprobar las distintas ocupaciones y las diferencias salariales: en algunos casos el salario de la mujer es incluso inferior al del niño. A todo ello se unen las condiciones laborales que perjudican gravemente su salud. La esposa era también una competidora frente al marido puesto que en aras de la escasa retribución que cobraba, era preferida al varón.

La primera Ley de mujeres y niños, de 13 de marzo de 1900, surge después de los trabajos de las Comisiones Provinciales y Locales de Reformas Sociales. Un proyecto que, junto a la Ley de accidentes de trabajo, se anuncia ya en la reestructuración de la Comisión de Reformas Sociales en 1890. Las respuestas al cuestionario aportaban una solución legislativa con el protagonismo indiscutible de Eduardo Dato. Una ley protectora exclusivamente de los niños y de las mujeres que a la larga conduce o puede conducir, según algunos autores, a la exclusión femenina de esferas importantes del mercado de trabajo, y a su vez a la relegación de su actividad al ámbito doméstico pues su contratación resultaba más costosa. La fragilidad femenina, la maternidad o el puerperio, contribuyen a apartar a la mujer de ciertas actividades que son ocupadas por hombres. Una estructura patriarcal rige en la familia y en el mercado de trabajo.

Si analizamos el contenido de las primeras normas de carácter social dirigidas a proteger a la mujer se refieren continuamente a su fisiología como portadora de vida y a la moralidad que puede resultar quebrantada por la relación con el otro sexo. El tema del salario era obvio: debía ganar menos que el hombre. Los motivos más variados lo justifican y también los hemos visto en las respuestas recogidas en páginas anteriores. La diferencia salarial continua entre unos y otros trabajos y entre diferentes períodos

\footnotetext{
${ }^{96}$ Reformas Sociales, Tomo II, cit., p. 164. Informe de D. Alejandro San Martín.

${ }^{97}$ Reformas Sociales, Tomo V, cit., p. 613-614. Memoria de la Comisión de la provincia de Vizcaya. Informe del ponente Ricardo Ortiz a las cuestiones XIV y XV del cuestionario.

${ }^{98}$ Reformas Sociales, Tomo III, cit., p. 559, Apéndice núm. 52, Informe del Presidente de las Sociedades cooperativas de Ruzafa.
} 
históricos.

El convenio C100 de la OIT sobre igualdad de remuneración, fue adoptado por la $34^{\mathrm{a}}$ reunión de la CIT el 29 de junio de 1951. Define el término "remuneración" y la expresión "igualdad de remuneración” designa las tasas de remuneración fijadas entre la mano de obra masculina y femenina, por un trabajo de igual valor sin discriminación en cuanto al sexo. El convenio, considerado fundamental entró en vigor el día 23 de mayo de 1953. La historia aún continúa.

\section{Bibliografía}

Álvarez JunCO, J., "La Comisión de Reformas Sociales: Intentos y realizaciones" en De la beneficencia al bienestar social, Seminario de Historia de Acción Social, Madrid, Consejo General de Colegios Oficiales de Diplomados en Trabajo Social y Asistentes Sociales-Siglo XXI, 1986, pp. 147-153

ARIAs De Velasco, J., "El derecho y la caridad" en Revista General de Legislación Jurisprudencia 83 (1893) pp. 40-57.

BALCELls, A., Trabajo industrial y organización obrera en la Cataluña contemporánea 1900-1936, Barcelona, Laia, 1974.

BERnAldo De QuiRós, C., "El Instituto de Reformas Sociales" en Revista de Trabajo 25 (1969), pp. 153-158 y a la Revista General de Legislación y Jurisprudencia 122 (1913), pp. 209-216

Calle Velasco, M. D., de la, La Comisión de Reformas Sociales, 1883-1903. Política social y conflicto de intereses en la España de la Restauración, Madrid, Ministerio de Trabajo y Seguridad Social, 1989

CAstillo, S., "El reformismo en la Restauración, Del Congreso Sociológico de Valencia a la Comisión de Reformas Sociales" en Estudios de Historia Social 30 (1984), pp. 21-78.

DATO E IRADIER, E., "Significado y representación de las leyes protectoras del trabajo" a la Revista General de Legislación y Jurisprudencia, 114 (1909), pp. 5-28.

Elorza, A., Iglesias, M. C., "La fundación de la Comisión de Reformas Sociales" en Revista de Trabajo 25 (1969), pp.75-105. 
EsPunY TOMÁs, M. J., "La primera legislación social protectora de la mujer: una perspectiva comparada" en RAMOS VÁZQUEZ, I. (coordinadora), Derecho y Trabajo en el siglo XIX, Madrid, Dykinson, 2017, pp. 81-147.

EsPunY TOMÁs, M. J., "El servicio doméstico: la historia jurídica de una exclusión continuada" en ESPUNY TOMÁs, M. J./GARCIA GONZÁLEZ, G. (coordinadores), Relaciones laborales y empleados de hogar: reflexiones jurídicas, Madrid, Dykinson, 2014, pp. 27-60.

ESPUNY TOMÁs, M. J., "Políticas legislativas y regulación especial del trabajo a domicilio", VII Encuentro de investigadores sobre el franquismo, Universidad de Santiago de Compostela, 2010, pp. 17-26.

EsPuny ToMÁs, M. J., "Legislació histórica i Gènere" en BodElón, E./GiMÉNEZ, P., Desenvolupant els drets de les dones: àmbits d'intervenció de les polítiques de gènere, Barcelona, Diputación de Barcelona, 2008, pp. 15-31.

EsPunY TOMÁs, M. J., "El projecte de Llei d' intervenció obrera en la gestió de les industries" en YSÁS SOLANES, M., Segona República i Món Jurídic, Mataró, Editorial Càlamo, 2007, pp. 65-87.

EsPunY TomÁs, M. J., "Fisiologia i moral en la legislació social” en Àgor@ 2000, Jornades per la igualtat d'oportunitats i responsabilitats a la vida laboral i familiar, Barcelona, Generalitat de Catalunya, Institut Català de la Dona, 2001, pp. 137-141.

Espuny Tomás, M. J. , "Políticas de empleo y trabajo a domicilio ¿Una cuestión de género (1918-1926)?” en I Congreso Iberoamericano de relaciones laborales y recursos humanos (Sevilla, 28-29 de enero de 2016).

GARCIA NINET, J.I., "Elementos para el estudio de la evolución histórica del derecho español del trabajo: regulación de la jornada de trabajo desde 1855 a 1931”, en Revista de Trabajo $1^{\mathrm{a}}$ parte, 51(1975), pp. 40-132.

IGLESIAs, M. C. Y EloRZA, A., Burgueses y proletarios. Clase obrera y reforma social en la Restauración, Barcelona, Editorial Laia, 1973 y en Revista de Trabajo 25 (1969).

MARTinez Veiga, U., Mujer, trabajo y domicilio. Los orígenes de la discriminación, Barcelona, Icaria, 1995.

Marvaud, A., La cuestión social en España, Madrid, Ediciones de la Revista de 
Trabajo, 1975.

MonTERo GARCÍA, F., "La polémica sobre el intervencionismo y la legislación obrera en España: 1890-1900 (parte I): el debate académico" en Revista de Trabajo 59-60, 3er y $4^{\circ}$ trimestres 1980 , pp. 119-165.

Montoya Melgar, A., Ideología y lenguaje en las leyes laborales de España (18731978), Madrid, Civitas, 1992, pp. 28 y ss.

Palacio Morena, J. I., La institucionalización de la reforma social en España (18831924). La Comisión y el Instituto de Reformas Sociales, Madrid, Ministerio de Trabajo y Seguridad Social, 1988.

PÉRez GonzÁlez, V., "Apuntes sobre la cuestión social” en Revista General de Legislación y Jurisprudencia 100 (1902), pp. 566-582 y 101 (1902), pp. 5-25.

Reformas Sociales. Información oral y escrita publicada de 1889 a 1893. Edición al cuidado de Santiago CASTILlO, Madrid Centro de Publicaciones. Ministerio de Trabajo y Seguridad Social, 1985, Edición facsímil de la obra publicada por la Comisión de Reformas Sociales en la Imprenta de Manuel Minuesa de los Ríos con motivo del centenario de la creación de dicha Comisión.

Reformas Sociales. Tomo I, Información oral practicada por la Comisión de Reformas Sociales en Madrid, publicada en 1889.

Reformas Sociales, Tomo II, Información oral y escrita practicada por la Comisión de Reformas Sociales en la Madrid, publicada en 1890.

Reformas Sociales, Tomo III, Información oral y escrita practicada por la Comisión de Reformas Sociales en la provincial de Valencia, publicada en 1891.

Reformas Sociales, Tomo IV, Información oral y escrita practicada por la Comisión de Reformas Sociales en las provincias de Alicante, Ávila, Badajoz, Burgos y Cáceres, publicada en 1892.

Reformas Sociales, Tomo V, Información oral y escrita practicada por la Comisión de Reformas Sociales en las provincias de La Coruña, Jaén, Navarra, Oviedo, Palencia y Vizcaya. Publicada en 1893.

Ruiz De Grijalba, A., El contrato de trabajo ante la razón y el derecho, Madrid, 
Francisco Beltrán, 1902, 2a. Edición, 1922.

Scott, J. W., "La mujer trabajadora en el siglo XIX" en DubY, G. Y Perrot, M., Historia de las mujeres en Occidente, Tomo IV, Madrid, Taurus minor, 2000, pp. 427461.

SimON, J., L'ouvrière, Paris, Hachette, 1864, p. V.

Studia Historica, vol. II, no 4 (1984) dedicado a la Comisión de Reformas Sociales. 